\title{
Population exposure to urban highway traffic emissions
}

\author{
N. Barros, T. Fontes, C. Brás \& L. M. Cunha \\ Center of Environmental Modelling and Systems Analysis, \\ Fernando Pessoa University, Portugal
}

\begin{abstract}
In this paper is presented firstly the traffic and emission characterization of Via de Cintura Interna (VCI), an urban highway at Oporto city, Portugal, with more than 4000 vehicles/hour during rush hours. Emission estimates were carried through on the basis of emission factors to road transport published in the Atmospheric Emission Inventory Guidebook. A weighed emission factor has been calculated for nitrogen oxides $\left(\mathrm{NO}_{\mathrm{x}}\right)$ and vehicle class, according to the Portuguese fleet composition (vehicles age, type of engine and average speed). Furthermore, during a three-week period, an outdoor nitrogen dioxide $\left(\mathrm{NO}_{2}\right)$ monitoring campaign was carried out in a domain around the VCI $(100 \mathrm{~m}$ for each side), in particular near residential buildings. The results demonstrate that higher $\mathrm{NO}_{2}$ concentrations are seen in the sub-domain with higher circulation of heavy-duty vehicles and where buildings are adjacent to VCI hindering pollutant dispersion. Meteorological conditions, such as wind intensity and direction, temperature and solar radiation were monitorized too. The $\mathrm{NO}_{2}$ concentrations obtained by the monitoring campaign have been used to create scenarios of population exposure to $\mathrm{NO}_{2}$, having taken into account the time-activity patterns of residents. It was verified that higher exposures occur when the population lives in Boavista, in contrast with the favourable scenario that corresponds to life in Prelada and those working in Espinho city. The work and results presented in this paper are a part of the methodology used in the scope of the ImpactAir Project. This project, started in 2003 in Oporto city, has the main objective of evaluating the impact of urban highway (VCI) traffic emissions on air quality and the health of the local population.
\end{abstract}

Keywords: air pollution, traffic, population exposure, health risk. 


\section{Introduction}

Health effects of pollution are continuously under study. In 1999 it remained unknown whether the absolute concentration of pollution or the rate of change of concentrations had the greatest effect on different health end-points [1]. Epidemiological studies have confirmed the impact of air pollution on different respiratory health parameters and mortality. The effects of air pollution in population health depend directly from pollutants concentrations and exposure time and may be sharp or chronic. The knowledge of population health before the occurrence of harmful effects is important in the establishment of prevention programs [2]. Depending on the effects related to each substance, atmospheric pollutants are regulated with respect to different exposure times.

In urban environments and especially in those areas where population and traffic density are relatively high, human exposure to hazardous substances is expected to be significantly increased. This is often the case near busy traffic axis in city centers, where urban topography and microclimate may contribute to the creation of poor air dispersion conditions giving rise to contamination hotspots. High pollution levels have been observed in street canyons. Within these streets, pedestrians, cyclists, drivers and residents are likely to be exposed to pollutant concentrations exceeding current air quality standards [3]. Vehicular exhaust emission has gradually become the major air pollution source in modern cities and traffic related exposure is found to contribute significantly to total human exposure level [4]. Although technological improvements and more stringent emission standards have led to a remarkable reduction in emission levels for new vehicles over the last 25 years, these reductions are being counteracted by the continuing increase in traffic volumes [5]. There are studies focused on the association between road proximity and respiratory disease, lung cancer and stroke mortality. Some of these studies were conducted in countries across Europe [6, 7, 8] in United States [9, 10], in Hamilton, Canada [11], etc.

This paper focused on the study of population exposure to traffic emissions of VCI, in the scope of ImpactAir Project. VCI is an urban highway that crosses the city of Oporto, making the linking between Arrábida and Freixo bridges over Douro River. It serves not only the urban traffic, but also the long-range traffic between the main cities of the Peninsular Northeastern. As urban highway, VCI presents proper characteristics that distinguishes it from other arteries of Oporto city and the remaining highways of the country, provoking inevitably diverse environmental, socio-economic and health impacts.

\section{The ImpactAir project}

The main objective of the ImpactAir project (Urban Large Traffic Lines Impact on Health and Air Quality; The VCI Case) is to evaluate the emission impact of VCI on air quality and health of the local population. Additionally, a numerical model will be implemented and evaluated in order to predict the outdoor and indoor air quality near VCI and other Large Traffic Lines (LTL's). The 
numerical model should be a tool for people involved in urban planning and air quality management.

The project is divided in four tasks that consist of: indoor and outdoor air quality campaigns to measure traffic related pollutants; application of epidemiological questionnaires to sensitive and control groups; development, application and evaluation of a numerical model to predict emission impacts from traffic of VCI and other LTL's in air quality and health; and finally, the elaboration of a good practice manual to reduce those impacts and support politic decision maker.

\section{Methodology and results}

The methodology presented in this paper is a part of the work done in the scope of ImpactAir project. Firstly $\mathrm{NO}_{\mathrm{x}}$ emissions estimates were calculated on the basis of emission factors to road transport published in Atmospheric Emission Inventory Guidebook [12] and traffic counts in VCI during April 2004. At the same time, during a three-week period, an outdoor $\mathrm{NO}_{2}$ diffusive sampler monitoring campaign was carried out. Meteorological conditions, such as wind intensity and direction, temperature and solar radiation were also monitorized and have been taken in account. Finally, the results of this campaign and timeactivity patterns have been used to create scenarios of population exposure to $\mathrm{NO}_{2}$.

\subsection{Traffic analysis and emission estimates}

In this study 4 sub-domains of VCI were selected: Boavista, Prelada, Amial and Antas (Figure 1). In these sub-domains, strategic access points to center city with high traffic flow and sensitive zones (hospitals, schools, sport and residential zones) are placed.

\subsubsection{Traffic analysis}

The images recorded on video cameras located in the study sub-domains (Figure 1), have been used to do the traffic countings for vehicle category between $30 / 03 / 2004$ and $05 / 04 / 2004$. The differentiation of 5 vehicle categories was carried through having in account the definitions adopted by the Emission Inventory Guidebook [12], the Insurance Portuguese Institute [13] and the characteristic of VCI: passengers cars (PC), light duty vehicles (LDV), buses (B), heavy duty vehicles (HDV) and motorcycles (M) with more than 50 c.c. The countings have been done throughout 24 hours, in alternating periods of 15 minutes, in each felt of VCI, in a total of 8 days: 1 day in Amial (Wednesday), 2 in Antas (Tuesday and Saturday) and Boavista (Thursday and Monday) and 3 in Prelada (Saturday, Sunday and Monday).

The variation of daily average of traffic in VCI (Figure 2) evidences that minimum values of traffic happen during the night, between $04 \mathrm{H} 00$ and $05 \mathrm{H} 00$, while maximums between $08 \mathrm{H} 00$ and $19 \mathrm{H} 00$. In average, in VCI circulate about 107.000 vehicles/day in both directions, of which $82.6 \%$ are PC; $11.3 \% \mathrm{LDV}$; 
$5.4 \% \mathrm{HDV} ; 0.3 \% \mathrm{~B}$ and $0.4 \% \mathrm{M}$. This average distribution floats relatively little in each direction (Arrábida/Freixo or Freixo/Arrábida), but in the opposite, a significant difference is verified when weekend and workdays are compared, in particular for the categories of PC and HDV on Sundays, as expected, given the legislation in limiting the circulation of HDV in these days. The highest percentage of $\mathrm{PC}$ and $\mathrm{M}$ is verified in Prelada and Amial sub-domains (Figure 3), LDV and B in Antas and HDV in Boavista. Prelada is the sub-domain where the total flow of traffic is biggest and Antas the calmest sub-domain.

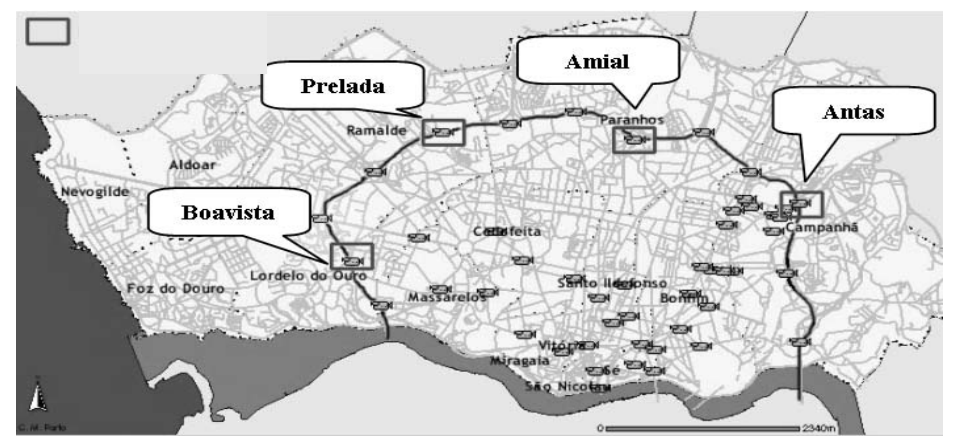

Figure 1: Locations of the video cameras in VCI sub-domains.

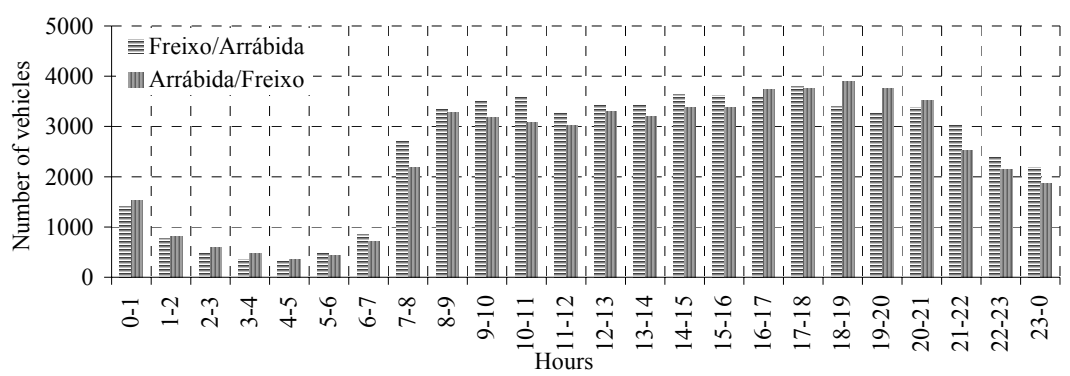

Figure 2: Daily average variation of traffic in VCI.

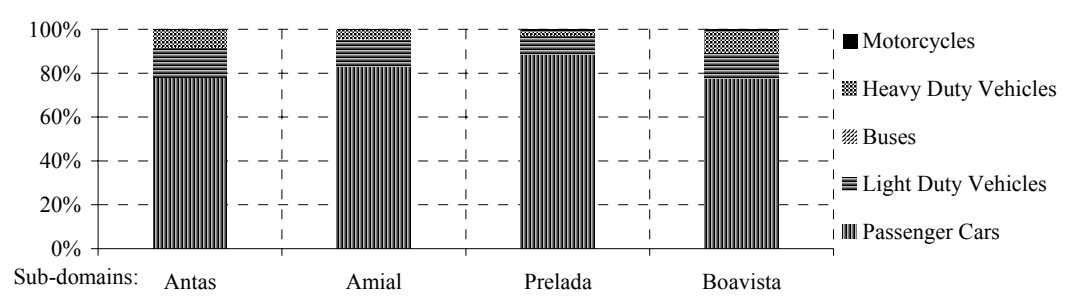

Figure 3: Average (\%) of vehicle categories in the 4 sub-domains. 


\subsubsection{Emission estimates}

For estimate traffic emissions, emission factors of road transport were used. These emission factors were selected by those published in the Atmospheric Emission Inventory Guidebook [12], and weighed in accordance with the Portuguese vehicle fleet composition in terms of certain parameters, as the average age of the vehicles, fuel, type of engine, tare and driving patterns in VCI [14]. The average speed of $20 \mathrm{~km} \cdot \mathrm{h}^{-1}$ was consider for rush hours with slow traffic movement and $75 \mathrm{~km} \cdot \mathrm{h}^{-1}$ for normal circulation. In this way, the weighed emission factors were calculated and applied to the traffic countings, getting hourly emissions, for NOx - Model LTE (Line Traffic Emissions) [14]. The higher emissions of NOx were seen in Boavista sub-domain while that less raised emissions were located in Antas sub-domain. The direction of traffic with bigger emissions was the Freixo/Arrábida.

\subsection{Outdoor $\mathrm{NO}_{2}$ diffuse sampler monitoring campaign}

To have a first idea of the most exposed and sensible zones to air pollution from traffic in the $\mathrm{VCI}$ area, a preliminary outdoor $\mathrm{NO}_{2}$ diffuse sampler campaign was carried out in April of 2004, in the 4 sub-domains: Antas, Amial, Prelada e Boavista. In each sub-domain have been defined 2 sampling lines of $\mathrm{NO}_{2}$ measurements, with intervals of 150 meters. Parallel to these, with a distance of 100 meters, another 2 lines for each one of the sides of the VCI was defined (Figure 4). The samplers (with an expanded uncertainty of $17,8 \%$ at concentration levels of 20-40 $\mu \mathrm{g} \cdot \mathrm{m}^{-3}$ ), in a total of 46 , had been placed between 3 and 10 meters of height to verify vertical concentration dispersion.

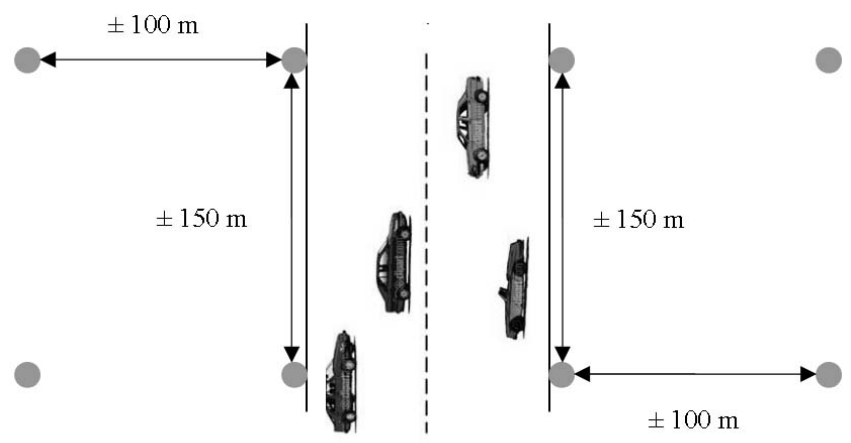

$\lceil\bigcirc$ Diffusive samplers

Figure 4: Scheme of the diffuse samplers location in VCI.

The results of the preliminary campaign showed that in all the sub-domains the $\mathrm{NO}_{2}$ concentrations are, in average, higher than $40 \mu \mathrm{g} \cdot \mathrm{m}^{-3}$, and that Boavista and Amial have the highest average values, 76,6 and 62,6 $\mu \mathrm{g} . \mathrm{m}^{-3}$, respectively. Prelada and Antas are the sub-domains that present a lower average concentrations with, $49,1 \mu \mathrm{g} \cdot \mathrm{m}^{-3}$ and $52,5 \mu \mathrm{g} \cdot \mathrm{m}^{-3}$, respectively. Comparing these results with the European Union Directive 1999/30/EC [15], it can be verified 
that Boavista, Amial and Antas sub-domains exceed the annual limit value for human health protection $\left(52 \mu \mathrm{g} \cdot \mathrm{m}^{-3}\right.$ for year 2004). The locals with higher concentrations of $\mathrm{NO}_{2}$ are the closest to $\mathrm{VCI}$, where average concentration reach values two times higher than ones located away from the VCI, about 100 meters. In most of the sampling points, the $\mathrm{NO}_{2}$ concentration diminishes with height, being exception locals surrounded by buildings, where the dispersion of pollutants becomes less efficient and, eventually, recirculation takes place. The influence of some closest streets and avenues with high flow traffic in the concentrations of the $\mathrm{NO}_{2}$ is remarkable, as it is on case of Amial Street, in the Amial sub-domain, and Boavista Avenue in the Boavista sub-domain (Figure 5).
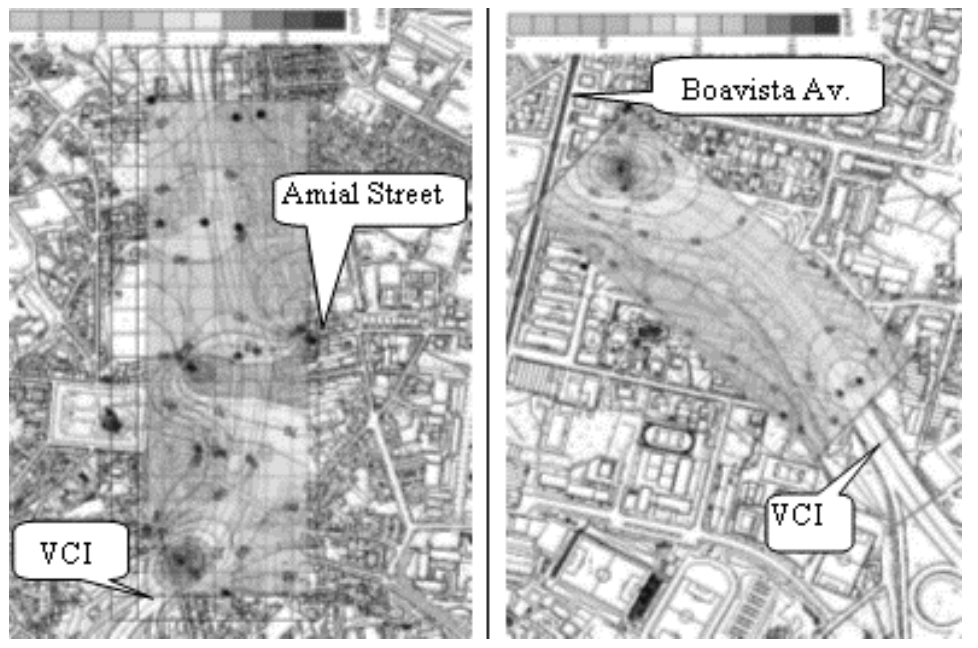

Figure 5: Results of the preliminary outdoor NO2 monitoring campaign in Amial and Boavista sub-domains (different scales).

\subsection{Meteorological parameters}

Meteorological factors influence the dynamics of the atmosphere, and the dispersion of the emitted pollutants. In the scope of the ImpactAir project, wind direction and speed, solar radiation and temperature were measured. The results obtained for the period of the preliminary outdoor campaign show that the average temperature value is $13,1^{\circ} \mathrm{C}$. Lowest values of temperature correspond to the sunrise and highest to the period of the afternoon between $12 \mathrm{H} 00$ and $17 \mathrm{H} 00$ UTC. As expected, solar radiation is null in the period of the night and in the daylight it reaches a maximum value at $13 \mathrm{H} 00$ UTC. Wind speed increases gradually during the day, reaching maximum values of between $14 \mathrm{H} 00$ and $16 \mathrm{H} 00$ UTC. With the end of the afternoon, wind speed starts to reduce, until reaching minimum values over night period. The analysis of the wind direction (Figure 6) demonstrates a North/Northwest and Southeast predominance. Having in account that in Boavista sub-domain the tracing of $\mathrm{VCI}$ is perpendicular to the direction of the predominant wind, the transport and dispersion of atmospheric 
pollutants emitted by traffic is strongly conditioned/limited by the existing buildings. This interpretation is consistent with the results of the preliminary campaign, where high values of $\mathrm{NO}_{2}$ were observed in this sub-domain and relatively lower values were observed in Prelada and the Antas sub-domains, which ones are more exposed to wind, facilitating the transport and dispersion of the emitted pollutants.

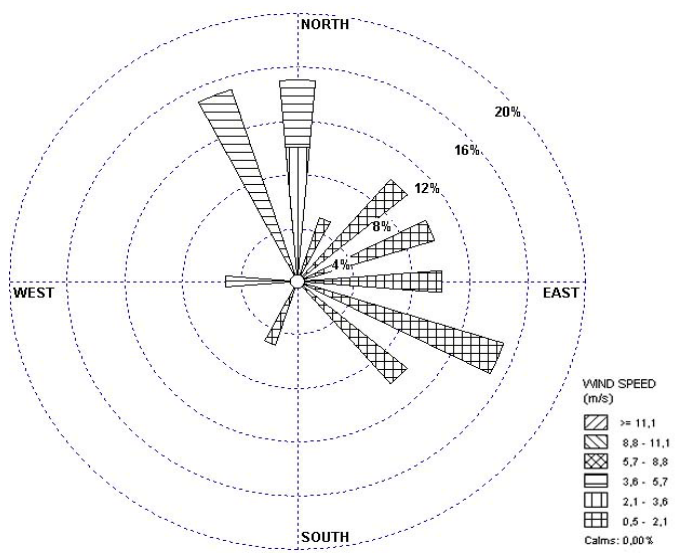

Figure 6: Wind direction and speed rose in the study area.

\subsection{Population exposure}

Several methods of measuring/estimating individual exposure have been used. This methods include passive portable monitoring equipment, which have the advantage that they can be used to determine individual exposures but also for establishing large-scale databases with indoor and outdoor data [16]. If the concentration of a pollutant to which a person is exposed can be measured or modelled and the time spent in contact with the pollutant is known, exposure is determined from concentration and time. It is often assumed that the concentration is constant within a given microenvironment $\mathrm{j}$ for some finite interval, $\Delta t_{j}$. Thus, any particular exposure $e_{j}$ within a given microenvironment $j$ is given by:

$$
e_{j}=\bar{C}_{j} \Delta t_{j},
$$

which means that a person stays within the microenvironment with average concentration $\bar{C}_{j}$ for the interval $\Delta \mathrm{t}_{\mathrm{j}}[17]$.

In this study, having in account the hour average concentrations of $\mathrm{NO}_{2}$ measured in the preliminary campaign and, for the same period, hour average concentrations of $\mathrm{NO}_{2}$ monitorized by the monitoring stations located in Oporto Metropolitan Area, exposition scenarios were defined. In a first stage it was evaluated in which cities of the Oporto Metropolitan Area (Figure 7) work the residents of Oporto city, using an origin/destination data matrix work trips [18]. 
The highest number of trips was verified for Oporto and Matosinhos cities, while the lowest was verified for Espinho. Assuming that an individual lives in the VCI domain (Boavista, Prelada, Amial or Antas), staying at home or around of it during 15 hours and works in Oporto, Matosinhos or Espinho city during a period of 9 hours a day, 12 exposure scenarios have been made. Examples of these scenarios are: the individual lives in Amial sub-domain (15 hours) and works in Espinho (9 hours).

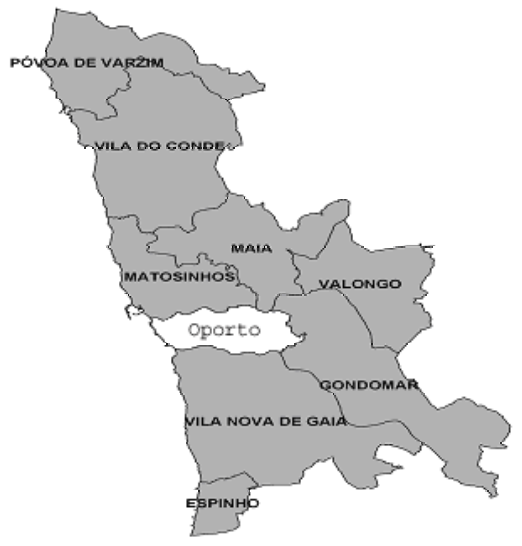

Figure 7: $\quad$ Map of Oporto Metropolitan Area.

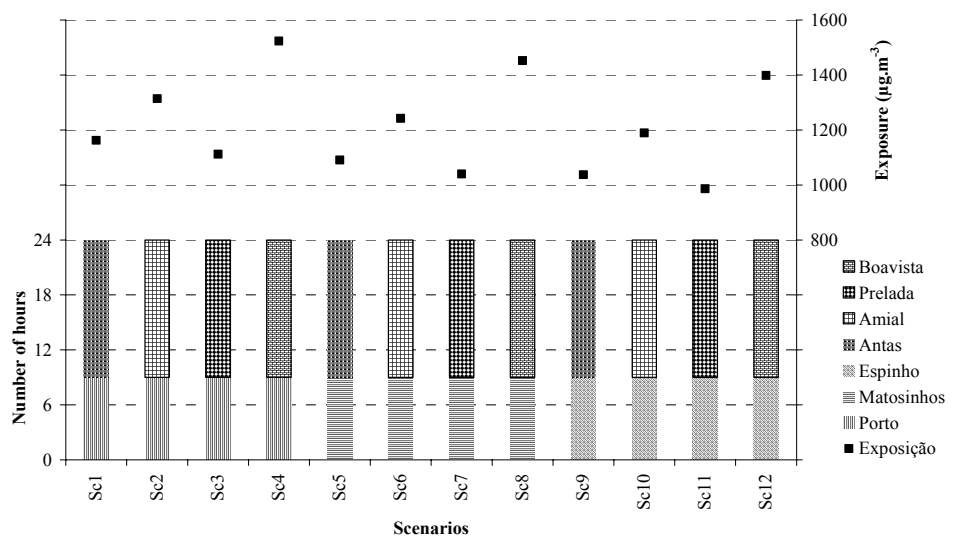

Figure 8: $\quad$ Exposure scenarios for $\mathrm{NO}_{2}$.

As it is observed in Figure 8, the worst scenario (with higher exposition of an individual to $\mathrm{NO}_{2}$ ) is that where population lives in Boavista and works in Oporto city center, followed by those scenarios where the individual lives in Boavista and works in Matosinhos and/or Espinho. The favourable scenario is that one the population lives in Prelada and works in Espinho. 


\section{Conclusions}

The analysis of daily traffic variation in VCI sub-domains allowed to evidence that the biggest flow of traffic is verified in Prelada, in contrast with Antas, the calmest sub-domain. Although traffic flow in Boavista is not so intensive as in Prelada, $\mathrm{NO}_{2}$ measurements showed higher concentrations. This can be explain by the fact that in Antas and Prelada sub-domains there are few constructions in height and some agricultural fields, what having in account that the predominant wind is of the North/Northwest, with some frequency of Southeast, results in one better dispersion of pollutants, less loaded atmospheres. On the other hand, in Boavista sub-domain the number of HDV (diesel vehicles) in circulation is bigger than in the other sub-domains, what leads to an increase of the $\mathrm{NO}_{2}$ concentrations.

Atmospheric $\mathrm{NO}_{\mathrm{x}}$ emission estimations were in accordance with the results of the preliminary outdoor monitoring campaign, indicating that the higher $\mathrm{NO}_{2}$ emissions are verified in Boavista sub-domain.

According to the results of the preliminary outdoor campaign, the most problematic zones in terms of pollutants concentrations are those near VCI and at 3 meters of height. The concentrations tend to diminish in height, being exception, points involved by buildings, where the dispersion of pollutants becomes less efficient. It is still notable that in Boavista and Amial sub-domains, densely populated areas, $\mathrm{NO}_{2}$ average concentrations are above the established limit values [15], and, as such, preoccupying in terms of public health impact.

Relatively to the $\mathrm{NO}_{2}$ exposition scenarios, it was verified that higher exposure occurs when people lives in Boavista, in contrast with the favourable scenario that corresponds to live in Prelada and work in Espinho.

\section{Acknowledgments}

The authors wish to acknowledge the Science and Technology Foundation for financing the ImpactAir project (Ref. POCTI/ESP/47806/2002), and for the grant of Tânia Fontes (Ref. SFRH/BD/19027/2004). Special thanks go to City Council of Oporto, for traffic counts data provision.

\section{References}

[1] Guerreiro, C., Clench-Aas, J. \& Bartonova A., Air pollution exposure monitoring and estimating. Part III. Development of new types of air quality indicators. Journal of Environmental Monitoring, 1, pp. 327-332, 1999.

[2] Regional Administration of Health - Center of Portugal. Air quality and public health - Occurrence of respiratory diseases. October 2001-March 2002.

[3] Vardoulakis, S., Fisher, B.E.A., Pericleous, K. \& Flesca, N.G., Modelling air quality in street canyons: a review. Atmospheric Environment, 37, pp. 155-182, 2003. 
[4] Chan, L.Y., Chan, C.Y. \& Qin, Y., The effect of commuting microenvironment on commuter exposures to vehicular emission in Hong Kong. Atmospheric Environment, 33, pp. 1777-1787, 1999.

[5] $11^{\text {th }}$ International Symposium, Transport and Air Pollution. Graz, Austria 19-21 June 2002. Atmospheric Environment, 37, pp. 5135-5136, 2003.

[6] Wyler, C., Fahrlander, C. B., Kunzli, N., Schindler, C., Liebrich, U. A., Perruchoud, A., Leuenberger, P. \& Wuthrich, B.; the Swiss Study on Air Pollution and Lung Diseases in Adults (SAPALDIA Team), Exposure to motor vehicle traffic and allergic sensitisation. Epidemiology, 11, pp. 450-456, 2000.

[7] Hoek, G., Brunekreef, B., Goldbohm, S., Fischer, P. \& van den Brandt, P. A., Association between mortality and indicators of traffic-related air pollution in the Netherlands: a cohort study. The Lancet, 360, pp. 1203, 2002.

[8] Maheswaran, R. \& Elliot, P., Stroke mortality associated with living near main roads in England and Wales. Stroke, 34, pp. 2776-2780, 2003.

[9] English, P., Neutra, R., Scalf, R., Sullivan, M., Waller, L. \& Zhu, L., Examining associations between childhood asthma and traffic flow using a geographic information system. Environmental Health Perspectives, 107, pp. 761-767, 1999.

[10] Langholz, B., Ebi, K. L., Thomas, D. C., Peters, J. M. \& London, S. J., Traffic density and the risk of childhood leukaemia in Los Angeles casecontrol study. Annuals of Epidemiology, 12, pp. 482-487, 2002.

[11] Jerrett, M., Arain, A., Kanaroglou, P., Beckerman, B., Potoglou, D., Sahsuvaroglu, T., Morrison, J. \& Giovis, C., A review and evaluation of intraurban air pollution exposure models. Journal of Exposure Analysis and Environmental Epidemiology, 15, pp. 185-204, 2005.

[12] EMEP (2002) Emission Inventory Guidebook - Technical report $n^{\circ} 30,3^{\circ}$ Edition, European Environment Agency, Copenhagen.

[13] Insurance Portuguese Institute. Parque Automóvel Seguro 2000-2001, Portugal.

[14] Barros, N., Fontes, T. \& Brás, C., Comparação das Emissões do Tráfego Rodoviário por Análise dos Factores de Emissão, Department of Science and Technology Magazine, Fernando Pessoa University, 1, pp. 29, 2004.

[15] Council Directive 1999/30/EC of the 22 April 1999 relating to limit values for sulphur dioxide, nitrogen dioxide and oxides of nitrogen, particulate matter and lead in ambient air.

[16] Committee on Advances in Assessing Human Exposure to Airborne Pollutants, Human exposure assessment for airborne pollutants: advances and opportunities. U.S. National Academy of Sciences, 1991.

[17] Committee on Risk Assessment of Hazardous Air Pollutants - National Research Council Science and judgment in risk assessment. The National Academies Press, 672 pages, 1994.

[18] National Institute of Statistics. Inquérito à Mobilidade da População Residente, Portugal, 2000. 